RU Профессиональные деформации преподавателей региональных вузов

Болтенков Н. В., Гринько А. А.

Аннотация. Цель исследования заключается в выявлении профессиональных деформаций преподавателей вузов на региональном уровне. В статье рассматриваются характерные особенности профессии преподавателя на современном этапе развития высшего образования; факторы, закладывающие основы для появления и усиления профессиональных деформаций педагогов региональных вузов; раскрываются наиболее распространенные проявления деформаций с их краткой характеристикой. Научная новизна работы заключается в том, что авторы провели исследование проблемы профессиональных деформаций среди профессорско-преподавательского состава ряда региональных вузов, проанализировали полученный эмпирический материал и выявили наличие обратной зависимости между степенью выраженности деформаций и удовлетворенностью трудом со стороны педагога, между прогрессией деформаций преподавателей и качеством контингента обучающихся, а также связь между степенью «выгорания» и предметной областью педагога. В результате выявлены факторы, способствующие формированию деформаций преподавателей на региональном уровне, проявления деформаций, прослежены стадии развития профессионального «выгорания» и определены основные группы риска, отмечено, что наибольший риск профессиональных отклонений характерен для преподавателей, не имеющих ученых степеней и званий, а также в возрасте 40 лет и старше.

\title{
Professional Deformations of Teachers at Regional Universities
}

\author{
Boltenkov N. V., Grinko A. A.
}

\begin{abstract}
The purpose of the research is to identify professional deformations of university teachers at the regional level. The paper examines the distinguishing features of the teaching profession at the present stage of higher education development; considers factors that form the basis for the emergence and intensification of teachers' professional deformations at regional universities; sheds light on the most common manifestations of deformations and provides their brief characteristics. Scientific novelty of the work lies in the fact that the authors have studied the issue of professional deformations among the teaching staff of a number of regional universities, have analysed the empirical material obtained and have found an inverse relationship between the severity of deformations and job satisfaction on a teacher's part, between the progression of teachers' deformations and the quality of the student body, as well as the correlation between the severity of "burnout" and a teacher's subject field. As a result, factors contributing to the emergence of teachers' deformations at the regional level have been identified, as well as their manifestations, the stages of development of professional "burnout" have been outlined and the main risk groups have been identified. It has been noted that the greatest risk of professional deviations is characteristic of teachers who do not hold academic degrees and ranks, as well as those aged 40 and over.
\end{abstract}

\section{Введение}

Актуальность темы статьи заключается в том, что профессия педагога по-прежнему остается одной из важнейших для человеческого общества. Несмотря на развитие цифровых технологий и все большее распространение самообразования, реальный преподаватель продолжает оставаться ключевой фигурой образовательного процесса, ему принадлежит определяющая роль в развитии личности студента и формировании его профессиональной компетентности. Профессия педагога в психологическом плане является одной из самых сложных и напряженных, поскольку входит в группу профессий с большим количеством стресс-факторов. Новые стандарты высшего образования, ускоренные процессы внедрения элементов дистанционного обучения, необходимость постоянного поиска эффективной коммуникации со студентами, развитие практики эффективных трудовых контрактов, основанных на многочисленных показателях, и другие факторы способствуют появлению различного рода профессиональных деформаций, выявлять и предотвращать развитие которых 
необходимо всем участникам образовательной сферы. Проблема профессиональных деформаций особенно актуальна на региональном уровне в силу более острого влияния на педагогов местных вузов ряда факторов, таких как качество базовой подготовки абитуриентов, финансовое благополучие, карьерные перспективы и др.

Для достижения поставленной цели требуется решить следующие задачи:

- выявить факторы, способствующие появлению профессиональных деформаций преподавателей региональных вузов;

- описать проявления профессиональных деформаций преподавателей в организациях высшего образования регионального уровня.

Теоретической базой исследования послужили работы отечественных исследователей, изучавших различные аспекты проблемы профессиональных деформаций в педагогической среде. Так, Н. И. Медведева и И. А. Усачева (2012) рассматривали особенности деформаций в отношении учителей общего образования; Л. М. Зотова (2013) анализировала проявления деформаций в среде женщин-педагогов; Н. И. Федотова (2017), А. Г. Фролов (2015), О. Б. Полякова (2014) обращали внимание на динамику проблемы в системе высшего образования; М. Г. Зубаков и В. В. Комаров (2010) характеризовали синдром эмоционального выгорания как проявление профессиональных деформаций.

В работе применялся целый комплекс исследовательских методов, к которым относились как теоретические методы (в частности, анализ научной литературы и источников по проблеме), так и эмпирические методы (например, наблюдение, анкетирование, анализ полученных экспериментальных данных).

Практическая значимость работы заключается в том, что были выявлены основные профессиональные деформации, характерные для преподавателей региональных образовательных организаций высшего образования, и группы риска среди педагогов. Полученная информация подтверждает важность проблемы профессиональных деформаций педагогов и может быть использована при разработке мер для профилактики таких состояний и повышения эффективности деятельности вузов.

\section{Факторы, способствующие появлению профессиональных деформаций преподавателей региональных вузов}

В настоящее время отечественное высшее образование претерпевает перманентные изменения, прямо влияющие на профессорско-преподавательский состав вузов. На уровне региональных организаций высшего образования это проявляется особенно остро. Увеличилась автономность профессии преподавателя, требующая напряженного умственного труда, повысилась степень профессиональной ответственности, произошло сопряжение функций педагога, исследователя и менеджера-управленца, возросла необходимость перманентного саморазвития и расширения спектра компетенций. Большие психоэмоциональные нагрузки становятся систематическим явлением, что приводит к психологическому дискомфорту и сказывается на состоянии здоровья педагога в самом широком плане. Психологические и интеллектуальные перегрузки, возникающие на фоне этого, приводят к появлению и усилению так называемых профессиональных деформаций - изменений сложившейся структуры деятельности и личности, негативно сказывающихся на продуктивности труда и взаимодействии с другими участниками образовательного процесса (Полякова, 2014).

Исследователи Э. Ф. Зеер и Э. Э. Сыманюк (2005) определили несколько главных групп факторов, которые вызывают профессиональные деформации. К ним относятся объективные факторы, «связанные с социальнопрофессиональной средой, социально-экономической ситуацией, имиджем и характером профессии, профессионально-пространственной средой»; субъективные факторы, «обусловленные особенностями личности и характером профессиональных взаимоотношений»; объективно-субъективные факторы, «порождаемые системой и организацией профессионального процесса, качеством управления, профессионализмом руководителей» (с. 72).

Ежегодно возрастают требования к педагогам, каждый из которых в условиях значительной учебной нагрузки должен являться мультидисциплинарным специалистом, умеющим принимать нестандартные решения, использовать современные средства и приемы обучения, повышать компетентность, грамотно выстраивать коммуникацию с обучающимися и быть образцом порядочности и нравственности (Зубаков, Комаров, 2010).

Преобразования последних лет, которые привели к тому, что образование стало рассматриваться в качестве рыночной услуги, способствовали снижению у педагогов позитивного отношения к любым нововведениям в системе образования и развитию пассивности (Федотова, 2017). Формальные критерии, отражающие эффективность образовательного процесса, а также рейтинговые показатели, на которые должны ориентироваться педагоги, нередко подменяют собой истинные ценности и главный смысл педагогической деятельности - социализацию поколений (Логунова, Уткина, Коваленок и др., 2019). При этом педагоги обязаны систематически повышать свой образовательный, воспитательный, научный и методический уровень, что обусловлено многочисленными формальными требованиями. Нормы затрат времени педагога определяются неоднозначно и условно, так как помимо учебной работы преподаватель регионального вуза обязан заниматься научно-исследовательской, методической, воспитательной и иными видами работ (Фролов, 2015). Соответственно, преподаватель утрачивает профессиональный интерес, обращает чрезмерное внимание на негативные моменты в своей деятельности и склонен оставаться в шаблонных рамках без какого-либо проявления инициативности. Рост количества обучающихся, приходящихся на одного преподавателя, и возрастающая учебная нагрузка нивелируют чувство удовлетворения от работы. Индивидуализация в таких условиях полностью исчезает, а повышение качества обучения крайне незначительно. 
Профессиональная деятельность преподавателей региональных вузов в последние годы осуществляется в условиях постоянной нестабильности. Она, в частности, проявляется и в широко распространенной практике срочных (как правило, годичных) контрактов, для продления которых необходимо соблюдать целый комплекс требований, нередко довольно размытых и предполагающих большие временные затраты на их выполнение. В результате интенсивная и напряженная занятость преподавателя, сопряженная с высокой ответственностью, необходимостью принимать решения и находить выходы из кризисных ситуаций, способствует падению работоспособности, усилению утомления и истощения, утрате жизненной энергии, наконец, разочарованию в своей профессии.

Педагогическая деятельность в региональных образовательных организациях оказывается под большим административным прессингом, чем в крупных вузах федерального значения, возможности карьерного роста и профессионального развития ограничены, а местный студенческий контингент явно отличается от состава обучающихся в университетах-лидерах. Весомая часть обучающихся не имеет достаточного объема базовых общеобразовательных знаний, умений и навыков, которые должны были быть сформированы на предшествующем уровне общего образования. К этому добавляется недостаточная мотивация студентов и осознание ими того, что отчисление маловероятно. Коррупционная составляющая, отсутствие у ряда студентов элементарных представлений об этике, моральных принципах и деловом стиле общения с педагогом также характерны для многих региональных образовательных организаций. Современное студенческое сообщество скептически относится к знаниям, не подкрепленным экономическими достижениями, что приводит к нарушению эффективной коммуникации между преподавателем и обучающимися, нередко воспринимающими педагога как анахронизм, не соответствующий современной жизни. Данное утверждение основано на результатах опросов обучающихся вузов Амурской области, проводившихся в 2020-2021 годах. Более 65\% опрошенных студентов (всего было опрошено 150 человек, обучающихся на 1-4 курсах) в той или иной степени разделяют подобные взгляды.

По мнению О. Л. Лейбовича (2007), критерии оценивания деятельности педагога деформируются и меняют свое содержание. Так, требовательность может быть приравнена студентами к вымогательству или придирчивости, а стремление работать с действительно способными и увлеченными студентами воспринимается администрацией вуза как нежелание работать с отстающими. В результате преподаватель, придерживающийся традиционных принципов, становится деструктивным элементом со всеми вытекающими негативными последствиями для него.

Преподаватель регионального вуза ежедневно подвергается противоречивому воздействию с различных сторон. Во-первых, это обучающиеся, которые хотят получить понятные, интересные и практически полезные знания, но при этом отличаются склонностью к лени, минимальному приложению усилий, невысокой мотивацией, особенно к изучению общих дисциплин (история, философия, высшая математика).

Во-вторых, это администрация образовательной организации, которая требует от преподавателя высоких показателей качества работы, сопровождая это требование необходимостью подготовки значительного объема документации, а также обязывая преподавателя не допускать потери студенческого контингента в результате неуспеваемости, что означает приложение дополнительных усилий на откровенно «слабых» студентов, не способных осваивать образовательную программу.

В-третьих, это родители, влияние которых менее заметно, чем на уровне общего образования, но присутствует. В основном оно заключается в претензиях к вузу и отдельным преподавателям по поводу недостаточного качества обучения, излишней придирчивости педагога и занижения оценок. Отдельно можно выделить воздействие родных и близких педагога, политическую и социально-экономическую ситуацию в регионе и конкретном населенном пункте, природно-климатические условия, состояние здоровья и другие факторы, оказывающие влияние на преподавателя. Добавим сюда возросшую энергозатратность труда, интенсивность деятельности в режиме многозадачности, перманентность стресса и большую эмоциональную нагрузку. Все вышесказанное прямо влияет на формирование и развитие профессиональных деформаций, нарушающих целостность личности педагога и отрицательно отражающихся на продуктивности его труда.

Исследователи Т. В. Володина (2010) и Г. С. Корытова (2014) к причинам, вызывающим деформации, относят перманентную психологическую перегрузку, высокую ответственность педагогов и ролевые конфликты. Э. Э. Сыманюк и А. А. Печеркина (2010) добавляют к этому длительность рабочего дня и нехватку времени на ежедневный отдых, повышенную нервно-психическую напряженность педагогической деятельности; необходимость воспринимать большие объемы разнообразной информации; напряженные отношения в коллективе и давление со стороны администрации. Нельзя не согласиться с мнением Э. Э. Сыманюк и А. А. Печеркиной о том, что учебно-методическая деятельность связана с подготовкой многочисленной документации, что приводит к развитию у преподавателей формального подхода к обучению, утрате реального общения и творческого взаимодействия со студентами.

Основой профессиональных деформаций преподавателей региональных вузов могут выступать мотивы выбора преподавательской деятельности, в частности желание доминировать и самоутвердиться, имидж или материальные блага. Эти мотивы могут как осознаваться, так и быть неосознанными. Однако реальность отличается от романтизированного образа, сформировавшегося у молодого преподавателя. В результате неудачи и разочарования педагогов инициируют развитие негативных деформационных процессов. Степень выраженности деформаций определяется стажем работы, конкретным содержанием педагогической деятельности, а также индивидуально-психологическими особенностями личности (Зотова, 2013). 
Анкетирование, проводимое в ряде региональных университетов (Дальневосточный государственный аграрный университет, Амурский государственный университет, Благовещенский государственный педагогический университет), продемонстрировало наличие комплекса явлений, способствующих формированию профессиональных деформаций. В исследовании принимали участие 120 преподавателей в возрасте от 24 до 68 лет и стажем работы от 1 года до 45 лет. 80\% из них имело ученую степень и/или ученое звание. Преподавателям было предложено оценить различные аспекты своей деятельности по пятибалльной шкале (от 1 - «очень плохо» и до 5 - «отлично»). Несмотря на то, что по ряду аспектов педагоги указали высокие баллы (4,1 - морально-психологический климат в коллективе; 4,0 - свобода в стиле и методах проведения занятий; 4,0 - материальное стимулирование публикационной активности), по большему числу аспектов ситуация оказалась более проблемной. Так, недовольство высказывалось слабой возможностью участия в выездных конференциях и повышения квалификации (2,3 балла); увеличением числа предметов, преподаваемых одним педагогом (2,7 балла); излишней бюрократизацией внутриуниверситетских процессов (2,5 балла); большим объемом работы с неуспевающими студентами (2,5 балла). Что касается последнего, то, безусловно, преподавателю выгодно, чтобы студенты могли пройти промежуточную аттестацию с первого раза, поскольку дальнейшая работа с данной категорией обучающихся нередко строится лишь на энтузиазме педагога и осуществляется без материального стимулирования. В ходе анкетирования было выявлено, что неудовлетворенность деятельностью более характерна для «остепененных» педагогов старше 40 лет вне зависимости от пола, а также для преподавателей, не имеющих ученой степени и звания, старше 30 лет. Молодые преподаватели, а также педагоги, работающие на одну ставку, более удовлетворены своей работой.

Таким образом, в основе профессиональных деформаций преподавателей региональных организаций высшего образования лежит комплекс субъективных и объективных факторов, большей частью связанных с высокой интенсивностью и психологической напряженностью педагогической деятельности, а также обусловленных современными противоречивыми тенденциями развития образовательной сферы. Региональные особенности, связанные с качеством подготовки и мотивации обучающихся, ограниченность возможностей для профессионального и личностного роста, диктат со стороны администрации вуза и другие проявления прямо сказываются на формировании комплекса деформаций педагогов.

\section{Проявления профессиональных деформаций преподавателей в организациях высшего образования регионального уровня}

Исследователи Э. Э. Сыманюк и А. А. Печеркина (2010) утверждают, что профессиональная деформация у педагогов проявляется на нескольких уровнях. Во-первых, выделяется уровень общепедагогических деформаций, которые характеризуются сходными изменениями у большинства преподавателей. Во-вторых, это типологические деформации, которые проявляются в тех случаях, когда особенности личности педагога растворяются в соответствующих компонентах преподавательской деятельности. В-третьих, предметные деформации, которые обусловлены спецификой преподаваемой дисциплины. В-четвертых, индивидуальные деформации, проявляющиеся из-за индивидуальных особенностей личности преподавателя (Федотова, 2017). Составляющими профессиональной деформации преподавателя регионального вуза, как правило, являются такие качества, как агрессия, авторитарность, демонстративность, консерватизм, профессиональный догматизм, сверхконтроль, профессиональная индифферентность, социальное лицемерие, информационная пассивность и другие (Медведева, Усачева, 2012). Агрессия в профессиональном плане проявляется у преподавателей в иронии и насмешках, высокомерии и нетерпимости к критике, игнорировании прав обучающихся, враждебном отношении к неуспевающим или сложным обучающимся, в стремлении к централизации и радикальным методам ради создания атмосферы полного подчинения. Демонстративность является необходимой составляющей профессии преподавателя, однако в разумных пределах. В случае если она начинает проявляться в демонстрации своего превосходства, чрезмерном желании нравиться, излишне оригинальном поведении, то демонстративность выступает одним из элементов деформации, становясь средством самоутверждения. Консерватизм заключается в том, что преподаватель, особенно с опытом работы более 10 лет, использует для обучения неизменные учебные материалы, формы и методы. Это позволяет экономить личное время и силы педагога, но не способствует внедрению современных приемов обучения, насыщает образовательный процесс стереотипами и штампами, устаревшей информацией, формирует предубеждение против инноваций. Полная погруженность в педагогическую профессию, негибкое ролевое поведение в своей жизни, зацикливание на профессиональных проблемах и трудностях, назидательность и обвинительность в высказываниях, преувеличение роли своей дисциплины отражают ролевой экспансионизм. Педагогический догматизм формируется из-за систематических повторений одних и тех же ситуаций в образовательном процессе, что способствует формированию склонности к упрощению проблем и применению распространенных приемов без учета особенностей педагогической ситуации. Доминантность связана с выполнением преподавателем властных функций и проявляется в удовлетворении потребности во власти, в подавлении и самоутверждении за счет обучающихся. Сверхконтроль заключается в излишнем сдерживании своих чувств и тотальном контроле деятельности обучающихся. Профессиональная индифферентность порождается эмоциональной усталостью и негативным опытом от общения со студентами. Это приводит к черствости, 
сухости и равнодушию со стороны педагога. Социальное лицемерие обусловлено необходимостью оправдывать высокие нравственные ожидания обучающихся и общества в целом, пропагандировать моральные принципы и нормы поведения. Постепенно это превращается в привычку морализирования, формирует неискренность чувств и высказываний. Информационная пассивность преподавателя проявляется в нежелании повышать свою информационную компетентность, прекращении своего самообразования после накопления определенной знаниевой и методической базы для преподавания своего предмета (Медведева, Усачева, 2012; Федотова, 2017). Дидактичность выражается в стремлении преподавателя объяснить все самостоятельно, сопровождается чрезмерным нравоучением и назидательностью, в том числе и в личной жизни, приобретая характер занудства. В случае если ненормативное, отклоняющееся поведение обучающихся, например грубость, переносится на профессиональное поведение преподавателя, можно говорить о наличии поведенческого трансфера.

Профессиональные деформации развиваются постепенно и могут оставаться незаметными длительный период времени. Своеобразной ответной реакцией организма, своеобразным приемом психологической защиты выступает «выгорание», которое можно расценивать как одну из форм профессиональной деформации личности. «Выгорание» преподавателей вузов является неблагоприятной реакцией на рабочие стрессы и включает в себя психоэмоциональное истощение, проявляющееся в чувстве глубокой усталости и опустошенности; деперсонализацию - отрицательное или безразличное отношение к субъектам деятельности; утрату профессиональной мотивации, связанную с чувством некомпетентности и неуспешности в работе (Гунзунова, 2016). «Выгорание» приводит к возникновению и развитию существенных рисков для их психического и физического здоровья, терминальных заболеваний, сокращению средней продолжительности жизни преподавателя (Фролов, 2015).

По аналогии с исследованием, отраженным в статье Н. С. Пряжникова и Е. Г. Ожоговой (2014), было проведено исследование уровня профессионального «выгорания» у преподавателей трех региональных вузов Амурской области (Амурский государственный университет, Благовещенский государственный педагогический университет, Дальневосточный государственный аграрный университет). Исследование проводилось в форме анкетирования с последующей статистической обработкой результатов. В исследовании участвовали 100 педагогов в возрасте от 25 до 66 лет, их педагогический стаж составлял от 1 года до 44 лет. Полученные результаты свидетельствуют о значительной выраженности среди преподавателей элементов синдрома профессионального «выгорания». Эмоциональное истощение: высокая степень - у 40\% респондентов, средняя - у 30\%; деперсонализация: высокая степень - у 38,2\% респондентов, средняя - у 36,3\%; редукция профессиональных достижений: высокая степень - у 34,1\% и средняя - у 48,6\%. У более половины респондентов на фоне высокого психоэмоционального напряжения выявлены нравственные деформации, циничное отношение к труду, осознание своей неуспешности в сочетании с признаками профессиональной стагнации. С высокой долей вероятности можно считать, что данная картина характерна и для других регионов.

В статье Е. М. Мессиневой, Н. Б. Мануйловой и А. Г. Фетисова (2021) приводятся обзорные данные исследований в других региональных вузах России. Авторы выявили, что максимальный уровень профессионального «выгорания» наблюдается у преподавателей средней возрастной группы со стажем работы 11-20 лет. Было показано, что симптомы «выгорания» обычно более выражены у женщин, а также что к концу семестра у некоторых групп педагогов симптомы профессионального выгорания усиливаются. Все стадии развития «выгорания» чаще проявляются у преподавателей гуманитарных наук. Это связано с тем, что среди преподавателей технических дисциплин преобладают люди с логическим типом мышления, которым проще реагировать на сложные ситуации. Люди же с образным типом мышления, чаще встречающиеся среди преподавателей-гуманитариев, в большей степени эмоционально чувствительны, что косвенно может способствовать более быстрому развитию негативных синдромов профессионального «выгорания». Уровень «выгорания» выше у педагогов, обладающих высокой мотивацией к профессиональной деятельности. Почти 80\% опрошенных указали, что проблема профессионального «выгорания» для преподавателей вузов достаточно актуальна, больше половины респондентов считают, что «выгоранию» подвержены все сотрудники высших учебных заведений.

Таким образом, в среде преподавателей региональных вузов можно выделить различные проявления профессиональных деформаций и, в частности, «выгорание», которое встречается повсеместно. Эмоциональное истощение, деперсонализация и редукция профессиональных достижений особенно характерны для педагогов среднего возраста со стажем работы более 11 лет, преподавателей женского пола и гуманитариев.

\section{Заключение}

Подводя итоги, можно сказать, что профессия преподавателя регионального вуза является многогранной, сложной, насыщенной и предполагает необходимость постоянной мобилизации внутренних ресурсов.

В отличие от педагогов крупных образовательных организаций, расположенных в столице или имеющих статус национальных, федеральных университетов, региональные преподаватели более ограничены в возможностях своего профессионального развития, карьерного роста, в отстаивании своих прав в спорах с администрацией вуза, выборе дисциплин и в возможностях максимально раскрыть свой потенциал при работе с недостаточно мотивированной и подготовленной аудиторией.

Вышеназванные особенности усиливают стрессовый характер труда, сопровождающийся большой личной ответственностью, слабыми возможностями для самореализации, несоизмеримым соотношением трудозатрат 
и оплаты труда, неуверенностью в очередном продлении трудового договора со стороны администрации, что особенно проявляется в регионах. Повышенные требования к профессиональным качествам преподавателя, разочарование или сомнения в правильности профессионального выбора, трудности, провоцирующие стресс, относительно невысокий статус регионального педагога представляют собой факторы, способствующие профессиональным деформациям преподавателя. Их прогрессирование снижает продуктивность деятельности, отрицательно сказывается на профессиональной мотивации и наносит вред здоровью преподавателя. Развитию деформаций и, в частности, «выгорания» педагогов способствуют постоянное чувство усталости, подавленности, незащищенности, боязнь ошибок, неуверенность в собственных силах. На уровне регионального вуза имеет место наличие обратной зависимости между степенью выраженности деформаций и удовлетворенностью трудом со стороны педагога, между развитием деформаций преподавателей и качеством контингента обучающихся, а также существует связь между степенью «выгорания» и предметной областью педагога.

Спецификой профессиональных деформаций на региональном уровне является их хронический, перманентный характер. Профессиональные деформации начинают прогрессировать, как правило, постепенно и одновременно в нескольких проявлениях. Данные проявления нередко выходят за рамки педагогической сферы, оказывая негативное воздействие и на личную жизнь педагогов. Проведенные исследования подтверждают, что так или иначе более чем 2/3 преподавателей региональных вузов имеют те или иные деформации, следствием которых являются психическая напряженность, конфликты, кризисы и неудовлетворенность жизнью. К основным группам риска следует отнести преподавателей среднего возраста, имеющих стаж работы более 11 лет, а также не имеющих ученых степеней и званий. Женщины, а также педагоги-гуманитарии более, чем другие, склонны к «выгоранию». Результаты исследований свидетельствуют о необходимости отслеживания существующих и перспективных рисков для предотвращения профессиональных деформаций и, в частности, «выгорания», прежде всего в среде преподавателей, находящихся в средней возрастной группе, что является важной задачей администраций образовательных организаций.

Перспективы дальнейших исследований представляются в привлечении к анкетированию, а также интервьюированию большего контингента преподавателей образовательных организаций высшего образования, расположенных в различных регионах страны, и принятии во внимание дополнительных факторов, влияющих на появление профессиональных деформаций педагогов, таких как качество жизни жителей региона, экологическая обстановка, уровень безработицы, средняя зарплата по отраслям и т.д.

\section{Источники | References}

1. Володина Т. В. Особенности профессиональных деструкций у педагогов // Вектор науки Тольяттинского государственного университета. 2010. № 1 (1).

2. Гунзунова Б. А. Компоненты эмоционального выгорания у различных категорий педагогических работников // Мир науки, культуры, образования. 2016. № 1 (56).

3. Зеер Э. Ф., Сыманюк Э. Э. Психология профессиональных деструкций. М. - Екатеринбург: Академический проект; Деловая книга, 2005.

4. Зотова Л. М. Профессиональные деформации женщин-педагогов как предмет педагогического исследования // Гуманитарные и социальные науки. 2013. № 3.

5. Зубаков М. Г., Комаров В. В. Синдром эмоционального выгорания как проявление профессиональной деформации // Психолог и вызовы современного мира: мат. VIII Междунар. семинара молодых ученых и аспирантов / отв. ред. Н. А. Коваль. Тамбов: Бизнес-Наука-Общество, 2010.

6. Корытова Г. С. Профессиональная деформация личности в педагогической деятельности // Вестник Томского государственного педагогического университета. 2014. № 1 (142).

7. Лейбович О. Л. Преподаватель вуза: кризис идентичности // Высшее образование в России. 2007. № 2.

8. Логунова Л. Ю., Уткина А. Н., Коваленок Я. Г., Ушаков Д. В. Технологии благополучия деятельности преподавателя: проблемы измерения и понимания // Artium Magister. 2019. № 19.

9. Медведева Н. И., Усачева И. А. Диагностика профессиональных деформаций личности учителя общеобразовательной школы // Мир образования - образование в мире. 2012. № 1.

10. Мессинева Е. М., Мануйлова Н. Б., Фетисов А. Г. Проблема профессионального выгорания у преподавателей вузов // Мир науки. Педагогика и психология. 2021. № 2.

11. Полякова О. Б. Категория и структура профессиональных деформаций // Национальный психологический журнал. 2014. № 1 (13).

12. Пряжников Н. С., Ожогова Е. Г. Эмоциональное выгорание и личностные деформации в психологопедагогической деятельности // Вестник Московского университета. Серия 14 «Психология». 2014 . № 4.

13. Сыманюк Э. Э., Печеркина А. А. Противодействие профессиональным деформациям // Народное образование. 2010. № 9.

14. Федотова Н. И. Профессиональная деформация преподавателей высшей школы // Научные труды Московского гуманитарного университета. 2017. № 4.

15. Фролов А. Г. К проблеме профессионального выгорания преподавателя высшей школы // Наука, техника и образование. 2015. № 10 (16). 


\section{Информация об авторах | Author information}

RU Болтенков Николай Владимирович ${ }^{1}$, к. пед. н., доц. Гринько Андрей Александрович ${ }^{2}$, к. ист. н., доц.

${ }^{1}$ Амурский государственный университет, г. Благовещенск

2 Дальневосточный государственный аграрный университет, г. Благовещенск

EN Boltenkov Nikolay Vladimirovich ${ }^{1}, \mathrm{PhD}$

Grinko Andrey Aleksandrovich ${ }^{2}, \mathrm{PhD}$

${ }^{1}$ Amur State University, Blagoveshchensk

${ }^{2}$ Far Eastern State Agrarian University, Blagoveshchensk

${ }^{1}$ boltenkov1986@mail.ru,2andrey2007-85@mail.ru

\section{Информация о статье | About this article}

Дата поступления рукописи (received): 07.01.2022; опубликовано (published): 28.02.2022.

Ключевые слова (keywords): профессиональные деформации педагогов; профессиональное выгорание педагогов; региональный вуз; профессия преподавателя; профессорско-преподавательский состав; teachers' professional deformations; teachers' professional burnout; regional university; teaching profession; teaching staff. 